\title{
A LEAP Forward for Quantitative Literacy
}

\section{H. L. Vacher}

University of South Florida, vacher@usf.edu

Follow this and additional works at: https://digitalcommons.usf.edu/numeracy

Part of the Mathematics Commons, and the Science and Mathematics Education Commons

\section{Recommended Citation}

Vacher, H. L.. "A LEAP Forward for Quantitative Literacy." Numeracy 4, Iss. 2 (2011): Article 1. DOI: http://dx.doi.org/10.5038/1936-4660.4.2.1 


\title{
A LEAP Forward for Quantitative Literacy
}

\begin{abstract}
The Association of American College and Universities' Learning Education and America's Promise (LEAP) initiative has identified quantitative literacy (QL) as one of its Essential Learning Outcomes and classified it amongst five other Intellectual and Practical Skills such as inquiry and analysis, critical and creative thinking, and written and oral communication. This brings to mind a spreadsheet in which these transdisciplinary intellectual and practical skills are rows and academic disciplines are columns. With the view that the learning outcome QL is a row crossing mathematics and other disciplinary columns, this editorial considers how the papers in this and previous issues of Numeracy distribute into the imaginary spreadsheet. The analysis shows that papers in Numeracy have been expanding from the journal's cell of origin, where QL crosses mathematics, as well as growing in number. The editorial closes by asking about the uniformity of principles of QL from one cell to another in the row, and whether there are levels of QL within the row as a whole. A sidebar notes that downloads are passing the 15,000 mark and the monthly rate now is about $2 / 3$ higher than it was six months ago.
\end{abstract}

\section{Keywords}

quantitative literacy, learning outcome

Creative Commons License

(c) (1) (9)

This work is licensed under a Creative Commons Attribution-Noncommercial 4.0 License

\section{Cover Page Footnote}

Len Vacher is a professor of geology at the University of South Florida. He served on the charter board of the NNN and currently co-edits this journal. 
The Association of American Colleges and Universities (AAC\&U) was founded nearly a hundred years ago (1915) and now has more than 1,200 member institutions. ${ }^{1}$ The AAC\&U's mission is to promote liberal education, ${ }^{2}$ which it defines as "a philosophy of education that empowers individuals with broad knowledge and transferable skills, and a strong sense of value, ethics, and civic engagement."3 I italicize "transferable skills," because the AAC\&U clearly includes quantitative literacy (QL) among them and, in doing so, clearly speaks to the concept that QL crosses the curriculum.

This recognition of transdisciplinary QL is articulated by the AAC\&U's Learning Education and America's Promise (LEAP). Launched in 2005, LEAP "is a national initiative that champions the importance of a twenty-first century liberal education-for individual students and for a nation dependent on economic creativity and democratic vitality-.... (for all students) whatever their chosen field of study" (emphasis added). One of the cornerstones of this initiative is a set of Essential Learning Outcomes listed on the LEAP vision Web site. ${ }^{5}$ The Essential Learning Outcomes are classified under four headings: (1) knowledge of human cultures and the physical and natural world; (2) intellectual and practical skills; (3) personal and social responsibility; and (4) integrative and applied learning. QL is one of the six learning outcomes listed under Intellectual and Practical Skills. The other five are: inquiry and

\section{Fifteen Thousand Downloads}

The editorial for volume 3 , issue 1 , which went live January 1, 2010, was "Five thousand downloads." The 5k-download mark had been crossed October 20, 2009, about 22 months after the journal was launched. Using various curve fits, I estimated the 10,000-download crossing would occur between October 3, 2010, and March 2, 2011. It was December 22, 2010, some 14 months after the first 5k crossing. Now (early June 2011), we are at 14.3 thousand, on course to cross 15,000 on about the date this issue goes live, a little more than 6 months after the last $5 \mathrm{k}$ crossing. The train is rolling.

It appears to be more than inexorable acceleration; we seem to be in the midst of a surge. For example, so far there have been seven 6-mo. periods of the journal. During the first five, the 6mo. average downloads per month increased 12$18 \%$ from one 6 -mo. period to the next. Then, the increase from the fifth to the sixth jumped to $23 \%$ (from 328 to 403 dwnlds/mo). And, now, for the first five months of the seventh period, the average download per month rate has been 670 dwnlds/mo, or $66 \%$ higher.

The increased usage correlates with increased visibility brought about by behind-the-scenes activity of the USF Libraries. Numeracy is now indexed by the Directory of Open Access Journals. Google Scholar is indexing our keywords. Our DOIs and metadata are deposited into the CrossRef system. EBSCOhost started indexing this title in their Education Research Complete database starting in January.

${ }^{1}$ http://www.aacu.org/about/index.cfm (accessed June 10, 2011).

2 http://www.aacu.org/about/strategic plan.cfm\#Priority (accessed June 10, 2011)

3 http://www.aacu.org/resources/liberaleducation/index.cfm (accessed June 10, 2011)

${ }^{4}$ http://www.aacu.org/leap/index.cfm (accessed June 10, 2011)

5 http://www.aacu.org/leap/vision.cfm (accessed June 10, 2011) 
analysis; critical and creative thinking; written and oral communication; information literacy; and teamwork and problem solving. According to the LEAP vision Web site, these six skills are to be "practiced extensively, across the curriculum, in the context of progressively more challenging problems, projects, and standards for performance" (emphasis as in original). Nothing could be clearer: QL is an essential learning outcome for all students regardless of major, and it requires practice across the curriculum. Getting this concept out to 1,200 colleges and universities of all sizes and kinds is a major leap forward for QL.

The AAC\&U's articulation of QL as a learning outcome of college education has clarified for me what quantitative literacy (numeracy) is. As an editor of this journal, I have seen a lot of definitions of QL. Often they involve mathematics in some way; often there is an implication of "contained within" for the relationship between QL and mathematics, with modifiers such as "elementary" or "realworld" coming into play. Now, thanks to the AAC\&U's Essential Learning Outcomes, I don't think of QL so much in terms of its fit with crafted definitions as its position in a spreadsheet of the college educational experience (Fig. 1). For the columns we have the disciplines, including mathematics, statistics, and geology, to name only three. These are the province of the first category of Essential Learning Outcomes-knowledge of human cultures and the physical and natural world-which the LEAP vision Web site says is gained "through study in the sciences and mathematics, social sciences, humanities, histories, languages, and the arts." Students find them in the disciplinary silos of their institution (hence they are in the columns of the spreadsheet). The other categories of Essential Learning Outcomes, including the intellectual and practical skills, including QL, live in the rows. Students (can? should?) find them in any of the silos-mathematics, statistics, geology, to name the same three. Thus QL is not a part of mathematics; QL is a row, and mathematics is a column. QL crosses mathematics, and it crosses statistics, just as it crosses geology.

\begin{tabular}{|c|c|c|c|c|c|}
\hline & \multirow{2}{*}{$\begin{array}{c}\text { whole QL } \\
\text { row }\end{array}$} & \multicolumn{4}{|c|}{ institutional disciplines } \\
\hline & & math & statistics & geology & and all others .... \\
\hline \multicolumn{6}{|l|}{ inquiry and analysis } \\
\hline \multicolumn{6}{|l|}{ critical and creative thinking } \\
\hline \multicolumn{6}{|l|}{ written and oral communication } \\
\hline \multicolumn{6}{|l|}{ quantitative literacy } \\
\hline \multicolumn{6}{|l|}{ information literacy } \\
\hline teamwork and problem solving & & & & & \\
\hline
\end{tabular}

Figure 1. Spreadsheet showing learning outcome QL crossing disciplines.

So how might this view of QL apply to our current issue of Numeracy? I am imagining now that I am checking off (counting) where the ten titles in this issue land in my spreadsheet consisting of a smorgasbord of disciplinary columns and a single transdisciplinary row, QL (other journals can think about other transdisciplinary rows). 
- The following editorial by geologist Connor gives his view of the QL lesson to be learned from the March 11, 2011, disaster in Japan. Check the cells where QL crosses geology and where it crosses statistics.

- The paper by Kosko and Wilkins examines assessment items in TIMMS, PISA, NALS, and IALS. Two papers present new QL assessment instruments: Ward et al. for Miami University, and Sikorskii et al. for Michigan State University, respectively. For those three papers and this editorial, check the QL row itself, because they each relate to QL in general.

- The paper by Hassad develops a new teaching practice scale that identifies reform and traditional tendencies in teaching introductory statistics. Check two cells: where the QL row crosses statistics, and where it crosses education (pedagogy).

- Gilliland et al. apply the new QL assessment at Michigan State to explore the association of QL and financial literacy. Check cells where the QL row crosses such columns as business and economics.

- Boersma et al. adapt the AAC\&U VALUE (Valid Assessment of Learning in Undergraduate Education) rubric $^{6}$ for QL to grading student work in their Quantitative Reasoning in the Contemporary World course. Check the cells where the QL row crosses mathematics (the silo in which the course is housed) and journalism (the intended students).

- The paper by Henrich and Lee is a perspective developed from their experience of using service learning in a quantitative reasoning course as a means of helping students confront math anxiety. The column by Wallace applies the ideas of a system she has developed in previous columns to the teaching of algebra. For both of these, check the cell where the QL row crosses mathematics.

Thus of the ten titles in this issue of Numeracy, four result in a check for the QL learning outcome row itself (designate those as Category A); two make a check in the cell where the QL row crosses the mathematics discipline column (Category B); one makes checks both where QL crosses the mathematics column and where it crosses one or more other disciplinary columns (Category $\mathrm{C}$ ); and four make checks where the QL row crosses one or more disciplinary columns other than mathematics (Category D). The four categories are mutually exclusive. Putting the QL-general category (A) aside, there are more contributions (5) crossing one or more disciplines other than mathematics $(C \cup D)$ than those (3) crossing the mathematics discipline $(B \cup C)$. This is different than in the early days of Numeracy.

To see how Numeracy has been expanding outward from its cell of originwhere QL crosses the mathematics discipline-consider Figure 2, which displays

\footnotetext{
${ }^{6}$ http://www.aacu.org/value/ (accessed June 10, 2011).
} 
the four-category breakdown for articles, perspectives, notes, and guest editorials through the eight issues of Numeracy. For each of the first four issues (years 1 and 2 of the journal), papers checking non-math disciplines $(C \cup D)$ in my imagined spreadsheet make up $40 \%$ of the articles, perspectives, notes and guest editorials. For each of the last four issues (years 3 and 4), they make up 50\% or more. The contrast between those two time periods also includes a 20-60\% increase in the total number of articles, perspectives, notes and guest editorials. Numeracy is both growing and expanding its reach.

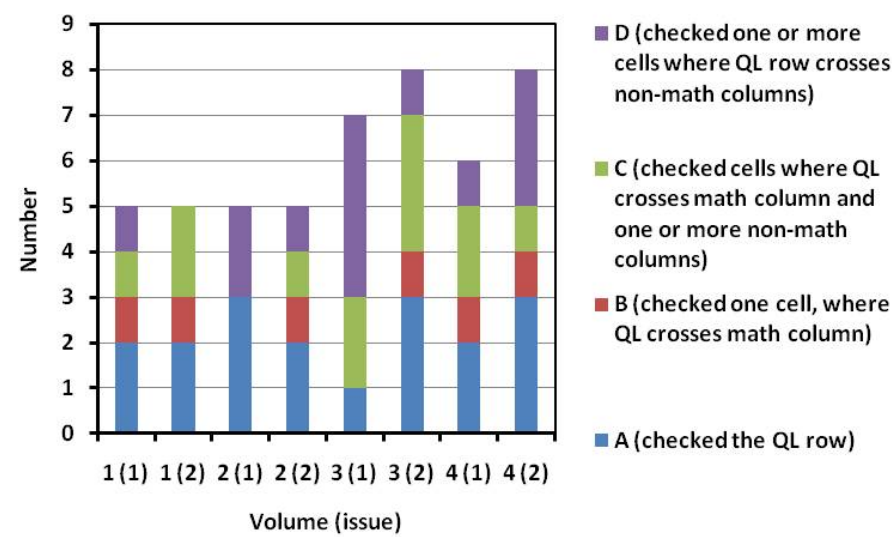

Figure 2. Classification of articles, perspectives, notes, and guest editorials in the first eight issues of Numeracy.
As Numeracy continues to expand across disciplines, we are interested in learning what numeracy is like in these other cells. Are there different levels of $\mathrm{QL}$ within the various disciplines?

For example, is a different level of QL expected for beginning graduate students in the discipline than for begin-

ning majors? Is the level for majors different than what is expected for students taking introductory service courses in the discipline? Are there QL principles? If so, do particular QL principles associate with particular disciplines, or do they cross disciplines uniformly? Do the principles become more sophisticated with level? Do students become more sophisticated in their numeracy as they go through their college experience? Or, is it sufficient that they simply become more fluent in elementary QL?

I am motivated to ask these questions in part because of Connor's editorial on the Fukushima Dai-Ichi disaster. The QL issue he raises-the hubris of deterministic analyses (his words) - is a sophisticated one, requiring the concept of and some sense about the tails of probability distributions and an understanding of the role of assumptions in deterministic models. While awareness of the tails of distributions can reside comfortably in the cell where QL crosses statistics (is that statistical literacy?), it is crucially relevant to decision making, as Connor argues. Shouldn't it roam to where the QL learning outcome crosses other disciplines as well? Shouldn't decision and policy makers know the difference between deterministic and probabilistic assessments when they need to act on consulting reports produced by former STEM majors who traveled the path to and through calculus on their way to deterministic models? 